\title{
UNIVERSIDAD TÉCNICA PARTICULAR DE LOJA TREINTA AÑOS HACIENDO EDUCACIÓN A DISTANCIA
}

\author{
(UNIVERSIDAD TECNICA PARTICULAR DE LOJA THIRTY YEARS OF PROVIDING DISTANCE \\ EDUCATION)
}

María José Rubio Gómez

Luis Miguel Romero Fernández

Universidad Técnica Particular de Loja (Ecuador)

\section{RESUMEN}

La experiencia de treinta años de Educación Superior a Distancia en la Universidad Técnica Particular de Loja viene a ser, en cierto sentido, expresión de la realidad de la Educación a Distancia en Latinoamérica. Analizamos, desde nuestra historia y el Modelo Bimodal de nuestra universidad, los hitos más importantes de la Educación a Distancia en general, que ha sido la revolución educativa más importante del siglo XX, proponiendo líneas claves de actuación para el futuro, y destacamos la necesidad de un auténtico enfoque sistémico para la misma y su integración con los diferentes elementos de una universidad compleja, centrada en el desarrollo de la investigación, socialmente pertinente y abierta internacionalmente, cuyo Modelo Educativo sea centrado en una visión prospectiva y humanística, alejado de teoricismos abstractos, y capaz de incluir de forma orgánica todos los aspectos de la realidad educativa y su contexto.

Palabras clave: educación a distancia, modelo educativo, sistema bimodal, experiencia, internacionalización, calidad, investigación.

\section{ABSTRACT}

The Universidad Técnica Particular de Loja has thirty years of experience in Distance Higher Education expressing, in some way, the actual status of Distance Education in Latin 
America. We discuss, from the point of view of our history and the dual educational system in our University, the most outstanding milestones of Distance Education in general (which is the most important educational breakthrough of the twentieth century) and propose future research lines. We must also mention the need for a genuine systemic approach for Distance Education and its integration with the different elements of a University which is focused on the development of research, linked to society and open to the world. The Educational Model of the University must be focused on a prospective and humanistic approach, away from theoricism, integrating all the aspects of the educational context in an organized way.

Key words: distance education, educative model, dual educational system, experience, internationalization, quality, research.

\section{LA EDUCACIÓN A DISTANCIA UNA EDUCACIÓN PARA EL SIGLO XXI. CONTEXTO LATINOAMERICANO}

La educación a distancia ha despertado un gran interés en la actualidad. Se ha visto en ella una herramienta enormemente valiosa para brindar capacitación, actualización y profesionalización a una población cada vez más numerosa con demandas y necesidades de formación diversificadas. Hay un aumento exponencial tanto en las universidades y entidades diversas que ofrecen este servicio educativo, como en el número de usuarios. El creciente número de estudiantes matriculados es, además, la mejor forma de difusión de esta modalidad, los alumnos potencian el interés en otros posibles usuarios y a la vez siguen matriculándose ellos mismos en nuevos programas o carreras. Este ha sido uno de los grandes fenómenos que hemos ido observando en nuestra Modalidad a Distancia a lo largo de más de 30 años de funcionamiento.

La importancia y reconocimiento internacional alcanzado por la educación a distancia, la han convertido en la mejor alternativa para responder a los retos de formación permanente y la universalización de la educación que esta sociedad globalizada reclama de manera creciente a las instituciones educativas, lo que a su vez precisa, a ritmos acelerados, una constante revisión de métodos, instrumentos y formas efectivas de llegar al estudiante con la acción formativa. Si al siglo XXI puede considerárselo como el siglo de la educación permanente y generalizada, que opta por la formación a distancia como la mejor alternativa, por la flexibilidad que nos ofrece para simultanear trabajo y estudio; el siglo XX, sin duda, fue el siglo de los que creyeron, soñaron y empujaron uno de los mayores acontecimientos educativos: la Educación a Distancia (EaD). 
En estos últimos años, la incorporación de las tecnologías de la información y la comunicación (TICs), han enriquecido enormemente a la EaD abriendo espacios nuevos para la interacción, la flexibilidad, e inmediatez en la actualización de los contenidos y en la asesoría a los alumnos. Esto debería, en principio, permitir superar las distancias de una forma enormemente efectiva; sin embargo, cuando se analiza en detalle la realidad de la llamada "modalidad virtual", al menos en el contexto latinoamericano, las realidades concretas suelen ser cientos de veces menores a la expectativa generada. Las razones son muy complejas, pero quizás la principal sea la falta de conexión de la oferta virtual con la realidad educativa como sistema integrado, que va mejorando los procesos para facilitar el aprendizaje y la comunicación, y que toma como base los fundamentos teóricos básicos de la Modalidad a Distancia, de la cual la "modalidad virtual" no es más que una muy interesante variante. En cambio se la ha visto como panacea que por sí sola solucionará los problemas o deficiencias que puedan darse en otros ámbitos del sistema educativo, o en su elemento principal, el modelo educativo.

De hecho, en los orígenes de la Modalidad a Distancia en Latinoamérica, los referentes fueron, fundamentalmente la Open University del Reino Unido y la Universidad Nacional deEducación a Distancia (UNED) deEspaña. Lamentablemente su traducción al contexto latinoamericano fue en base a universidades unimodales, en la mayoría de los casos, pero que a diferencia de aquellas, no tenían un verdadero claustro de profesores vinculados a unidades de investigación y desarrollo académico. Hacia mediados de los 80, las modas educativas fuertemente conductistas y relacionadas con diversas tendencias de las llamadas "ingenierías sociales", centradas en los modelos instruccionales, aprendizaje por dominio y evaluación por objetivos, detendrían el impulso inicial de la EaD y terminarían en gran medida trivializando sus logros educativos. Tal vez por esta razón, la novedad y expectativa inicial sólo llegó a prender en algunos países: México, Ecuador, Venezuela, y Costa Rica; sólo algo más tarde también en Colombia.

El desarrollo de las TICs, hacia mediados de los noventa, y los referentes de universidades totalmente virtuales como la Phoenix On-line o la Oberta de Catalunya, además de otras muchas en el contexto norteamericano que iban incorporando un intenso uso educativo de las TICs, generó una auténtica ola de interés por la "educación virtual" en Latinoamérica, aún vigente. Sin embargo, el uso de los diversos campus virtuales se hacía a través de unidades aisladas de diversas universidades, muchas veces descontextualizadas de la propia vida académica de las facultades o escuelas que los albergaban, y aún de sus propias universidades. Muchos se abocaron a una oferta educativa centrada en la capacitación o en postgrados cortos, y de nuevo con 
profesores que no eran parte de unidades de investigación, y que además se los contrataba esporádicamente. Fue una época muy centrada en el análisis de los más recientes avances de los diferentes campus virtuales y de diversas exquisiteces sobre lo especial que era estudiar on-line, pero que a la larga no llegó a producir un avance educativo cuantitativamente importante, como apuntábamos. Es sintomático que en esa época las universidades con un fuerte desarrollo académico, en países como Argentina, Chile o Brasil, fueran impermeables a esta innovación educativa, sólo en México se dio alguna relación entre calidad universitaria y EaD.

Desde estas premisas, queremos adentrarnos en nuestra propia historia, que es la de un crecimiento de nuestra Modalidad a Distancia y del quehacer académico de la universidad, acompañado por el reconocimiento social y la satisfacción personal que nos empujan a creer en la Modalidad a Distancia como un bien social de primera necesidad. Para que la Educación a Distancia sea verdadera educación universitaria, hemos de concebirla en su integralidad sistémica, perfectamente entroncada en las diferentes dimensiones de una universidad compleja que va incorporando los diferentes elementos de la realidad universitaria mundial, especialmente su crecimiento académico. Como más adelante veremos, la Modalidad a Distancia de nuestra universidad nació en el contexto de una universidad presencial, pero no como una dimensión separada de ella, sino como una universidad que incorpora las innovaciones educativas relevantes que van apareciendo en la vida institucional de la universidad. De hecho, actualmente la mayoría de las universidades del mundo con estudios a distancia responde a un cierto modelo bimodal. Sin embargo, el modelo bimodal integrado, que presentamos de nuestra universidad, lo creemos especialmente interesante para Latinoamérica ya que aprovecha las fortalezas de ambas modalidades: la Modalidad a Distancia y la Modalidad Presencial. No hablamos de una educación híbrida, es decir que alterne programas en una u otra modalidad sin relación, nos referimos a dos modalidades ofertadas por la misma universidad y coincidiendo en la oferta en la mayoría de los programas de estudio pero dirigidos a públicos diferentes. Estas modalidades, Presencial y a Distancia, con sus respectivos componentes virtuales, pueden compartir recursos, complementarse en sus fortalezas y minimizar las debilidades al aportar cada una, lo mejor que tiene, a la otra.

Por ejemplo, las instalaciones que se necesitan para la educación presencial son un componente valioso para la Modalidad a Distancia. Por otro lado la metodología de la Modalidad a Distancia, nos sirve para una innovación docente en la presencial, sobre todo, si los profesores son los mismos en ambas modalidades y a la vez están vinculados a los Centros de Investigación Transferencia de Tecnología Extensión y 
Servicios (CITTES) haciendo investigación aplicada que repercutirá sin duda en su docencia. Para asumir este modelo, necesariamente se ha de cambiar la tendencia latinoamericana de profesores vinculados a tiempo parcial, es necesario tener una mayoría de profesores vinculados con jornada completa para que a su vez, a la universidad le compense invertir en la formación de postgrado de sus docentes, especialmente de doctorado. Con ello, no sólo estaremos optimizando recursos, sino que tendremos producción científica con pertinencia social y aseguraremos una mejor docencia, en la que el uso de las diversas tecnologías educativas sea algo natural. Este ha sido el camino que la Universidad Técnica Particular de Loja emprendió decididamente hace casi una década, por lo que ya se empiezan a ver resultados.

\section{ÁMBITO LEGAL Y GÉNESIS DE LA EDUCACIÓN A DISTANCIA EN LA UNIVERSIDAD TÉCNICA PARTICULAR DE LOJA}

La Universidad Técnica Particular de Loja (UTPL), fue creada el 3 de mayo de 1971 por la Agrupación Marista Ecuatoriana (AME) y administrada por la misma, hasta octubre de 1997. Se crea al amparo del documento Modus Vivendi celebrado entre la Santa Sede y el Estado Ecuatoriano, teniendo en cuenta las normas de la Iglesia Católica en su organización y gobierno. El 27 de octubre de 1997, la Diócesis de Loja traspasa la administración de la UTPL por tiempo indefinido a la Comunidad de Misioneras y Misioneros Identes, por quien se encuentra regentada en la actualidad.

La UTPL es una institución educativa con finalidad social, sin fines de lucro, cofinanciada por el Estado Ecuatoriano, de conformidad con la Constitución Política de la República. Posee constitutivamente las modalidades de estudio: Presencial, Abierta y a Distancia. Está ubicada en la ciudad de Loja en la región sur del Ecuador, particularidad que resaltamos, porque a pesar de las dificultades, de no estar en la capital de la República, o en una ciudad céntrica, esto no ha sido un obstáculo invencible para dirigirse con la educación a distancia a todo el país.

El Consejo Gubernativo de la Universidad Técnica Particular de Loja, en la sesión del 2 de septiembre de 1976 crea la Universidad Abierta o Estudios a Distancia. Convirtiéndose así, en una de las universidades pioneras en Latinoamérica en esta modalidad. El Estatuto aprobado por el Consejo Nacional de Universidades y Escuelas Politécnicas (CONUEP), determinó, en sesiones del 27 y 28 de agosto de 1987, que la Universidad imparte estudios a través de las dos modalidades: Tradicional, Convencional o Presencial y Abierta o a Distancia. El Estatuto vigente, aprobado por el actual Consejo Nacional de Educación Superior (CONESUP) el 30 de enero del 
2002, establece en su art. 31 que la Universidad Técnica Particular de Loja brinda educación superior de pre y postgrado a través de las modalidades de estudio:

- Presencial y

- Abierta y a Distancia, con sus variantes:
o A Distancia tradicional
o Semipresencial y,
o Virtual

Desde el primer momento la Universidad Abierta de Loja, como se la denominó en un principio, nace como respuesta a la problemática educativa ecuatoriana, para atender la necesidad imperiosa de miles de hombres y mujeres que por distintos motivos: distancia, trabajo, situación económica... no podían acceder al sistema presencial de educación superior. En sus inicios optó por atender al Magisterio Nacional, ofreciendo el título de Profesor de Educación Media y las Licenciaturas en: Ciencias de la Educación y Lenguas y Lingüística. Se decidió impartir educación universitaria a distancia con amplia cobertura nacional, teniendo como sede matriz la ciudad de Loja. Inició las actividades regulares en octubre de 1976, con el primer ciclo de Ciencias Pedagógicas y Ciencias Básicas, en 34 Centros Asociados y 1.259 alumnos. En la actualidad cuenta con más de 20.000 alumnos y con 93 centros en todo el territorio nacional y 3 en el exterior. En su nacimiento, esta obra hubo de vivir la oposición y crítica de muchos sectores ya que se dudaba de su validez y eficacia; sin embargo, quienes confiaban en su aplicabilidad se mantuvieron firmes en la defensa, actitud que hoy se ha visto recompensada por la aceptación, respeto y reconocimiento nacional e internacional. Vale recordar que esta oposición a la educación a distancia ha sido un fenómeno que se ha dado a nivel mundial en sus comienzos, pero las cosas han variado de tal forma que, en algunos foros internacionales se cuestiona más bien lo contrario, con estas o similares palabras: "si será buena universidad aquella que no oferte hoy en día, de una u otra manera, educación distancia".

Desde una primera etapa, centrada en la formación de Profesores de Segunda Enseñanza y Licenciados en Ciencias de la Educación en sus diversas especialidades que fueron creándose paulatinamente $\mathrm{y}$, a través de un modelo pedagógico con énfasis en las Programaciones, se pasó en los primeros años de la década de los 90 al modelo instruccional, tan en boga en Latinoamérica, que ya hemos comentado. En 1994 se ofrece la carrera de Ciencias Jurídicas y en 1997 Contabilidad y Auditoría. Con la nueva administración en 1998 se abren 7 carreras más: Administración de Empresas, Administración en Banca y Finanzas, Secretariado Ejecutivo Bilingüe, 
Informática, Economía, Educación Básica, y Gestión Ambiental, en 1999 se ofertan las carreras de Administración en Gestión Pública, Psicología y Comunicación Social, y en el año 2000 la de Administración Turística. Es de destacar, en 1998, el cambio del modelo pedagógico por otro más universal y acorde con las nuevas tendencias constructivistas e integradoras que expondremos más adelante. En esa época se dio una difusión de la Modalidad a Distancia un tanto peculiar. Varios equipos de profesores y alumnos visitaron todas las localidades de más de tres mil habitantes en todo el país, presentando directamente la Modalidad a Distancia de la UTPL a las diferentes fuerzas vivas de la localidad. El resultado fue excelente, con la práctica duplicación del número de Centros universitarios asociados, que eran autogestionados, y la conciencia de que estábamos llegando con la educación superior a todo el país.

\section{IDENTIDAD INSTITUCIONAL}

\section{Visión de la UTPL}

Nuestra visión es el humanismo cristiano, que escogiendo por maestro al Cristo Histórico y el desarrollo de su pensamiento en la tradición de la Iglesia Católica, propugna una universidad potenciadora, conforme a la dignidad que el ser humano tiene como hijo de Dios, que hace que la universidad acoja, defienda y promueva en la sociedad, el producto y la reflexión de toda experiencia humana. Desde esta perspectiva concebimos la visión, más que como algo proyectivo de planteamientos propios, como horizonte al que tendemos y al que vamos adecuando la realidad universitaria. Se parece, en cierto sentido a lo que en otros contextos se lo denomina improvisación estratégica. Se va haciendo camino al andar, pero guiados por la referencia de los más altos horizontes, para lo que aprendemos de toda la experiencia universitaria, humanística y religiosa que podamos incorporar como valor.

\section{Misión de la UTPL}

Nuestro sueño es llevar a plenitud desde la visión del humanismo cristiano, los ideales que dieron origen a las universidades: Buscar la verdad y formar al hombre a través de la ciencia, para que sirva a la sociedad.

- Una verdad concebida como vectorial hacia donde dirigir nuestras más hondas dimensiones cognoscitivas, activas y vitales. 
- Una formación integral con propuestas educativas innovadoras que aúne las dimensiones científico-técnicas de calidad, con las humanísticas, éticas y espirituales.

- Un espíritu de investigación que contribuya al desarrollo de las ciencias experimentales y experienciales, referidas éstas a lo que da unidad, dirección y sentido a la vida humana.

- La docencia, la investigación y la extensión convergen hacia una gestión productiva, que trate de traducir la experiencia del amor en resultados concretos. Desde esa perspectiva el estudiante se hace sujeto y agente de su profesionalización y desarrollo humano, para servir a la sociedad en la que está inmerso.

\section{Valores institucionales}

La Universidad busca, en todos los espacios donde se realizan actividades de la comunidad universitaria, generar un ambiente que permita el desarrollo de los valores:

- Fidelidad a la visión y misión institucional

- Espíritu de equipo

- Capacidad de liderazgo y gestión

- Humildad socrática

- Flexibilidad operativa

\section{LA MODALIDAD ABIERTA Y A DISTANCIA EN LA ESTRUCTURA DE LA UTPL}

La Universidad Técnica Particular de Loja, como institución particular católica sin fines de lucro, cofinanciada por el Estado por su función social, designa sus autoridades y órganos de gobierno de conformidad al Estatuto vigente. El equipo de gobierno lo componen en orden jerárquico, las siguientes autoridades y estamentos:

- El Consejo Superior y el Consejo Tutelar

- El Rector-Canciller

- El Vicecanciller 
- Los Directores Generales ...

La ModalidadAbiertaya Distancia dela UTPL, esta contemplada en el organigrama institucional como una Dirección General, equivalente a un vicerrectorado, cuya competencia es matricial respecto al resto de Direcciones generales (Académica, de Investigación, Administrativo-financiera, etc.). Su gestión se la realiza a través de dos instancias:

\section{La Sede Central}

Desde la Sede Central se establecen y llevan todos los procesos académicos y legales. Desde ella se señala el modelo educativo y se imparten las directrices administrativas y económicas; se seleccionan los profesores, los materiales, la forma de evaluación y las tutorías generales a los alumnos. Es decir, es la única responsable de todo el acontecer de la Modalidad a Distancia. Está ubicada en la ciudad de Loja en el mismo campus de la Modalidad Presencial, ya que la Universidad es única pero con dos Modalidades con su organización específica. Ambas modalidades, cuya acción se centra en la docencia, comparten la relación con el resto de Unidades de Investigación, Extensión, Gestión y Relaciones.

Las diferentes Escuelas o Unidades Académicas, 24 en total, agrupadas en la Áreas Académicas Socio-Humanística, Administrativa, Técnica y Biomédica, son las unidades desde donde se lleva el control de los procesos académicos y de legalización de los estudios. Pueden ser bimodales o unimodales, y están vinculadas con los Centros de Investigación, Transferencia de Tecnología, Extensión y Servicio (CITTES) correspondientes, y con la Dirección de Modalidad Abierta y a Distancia y las Áreas de Coordinación de la gestión de la misma.

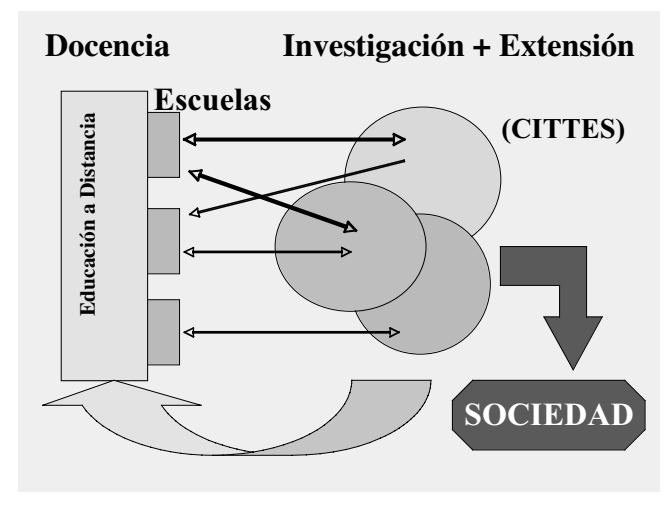


Hagamos un comentario referente a los CITTES. Los profesores de las universidades en los países desarrollados no sólo dan clases, sino que forman parte de unidades de investigación llamadas departamentos, institutos, laboratorios, etc. En tales unidades, definidas en torno a tópicos específicos, se relacionan con sus pares, desarrollan proyectos, cuentan con el equipamiento adecuado, participan en publicaciones y congresos, y transfieren sus resultados a la sociedad. Estos departamentos son centros de acumulación de capacidad instalada, a partir de los cuales tiene sentido la actividad docente, especialmente de postgrado. En muchas universidades los doctorados dependen directamente de tales unidades. El primer problema que nos planteamos es cómo generar desde cero tales unidades con las dificultades específicas de nuestro medio, tanto de personal, equipamiento, cultura científica, etc., como de presupuesto, ya que nuestra universidad cuenta aproximadamente con el mismo presupuesto por alumno que el resto de las universidades del país, incluso menos. Así fueron surgiendo lo que hemos denominado Centros de Investigación, Transferencia de Tecnología, Extensión y Servicios (CITTES), que es una versión "criolla" de los departamentos de las universidades de los países desarrollados, y por lo mismo inicialmente modesta. No es un modelo nuevo, es un intento de adecuación a lo que siempre han sido las universidades que nos permita equilibrar y potenciar mutuamente las dimensiones de docencia, investigación y extensión, que forman parte esencial de toda universidad.

En nuestra organización universitaria, los CITTES son estructuras complementarias con las Escuelas. La misión de éstas es la administración del currículo, y por tanto su énfasis es la docencia, presencial y/o a distancia. En cambio la misión de los CITTES es la ciencia y su aplicación, centrándose en las dimensiones universitarias de investigación y extensión o servicio a la sociedad. Son dos roles diferentes, pero las personas son las mismas. Nuestros jóvenes profesores-investigadores son parte de algún CITTES, donde colaboran en el desarrollo de la investigación en un área específica, que va concretándose en diversos proyectos, cada vez más elevados e interdisciplinares, dedicando para ello las dos terceras partes de su tiempo; pero a la vez son profesores, un tercio de su tiempo, de alguna Escuela, donde imparten sus conocimientos, de forma presencial o a distancia, cada vez más apoyados en las competencias específicas que van adquiriendo en los CITTES, el contacto con lo que se está haciendo en el mundo, la bibliografía, un sentido práctico y de pertinencia, la vinculación con ámbitos de la realidad relevantes a la aplicación de esas disciplinas, etc. La fase de madurez de los CITTES se da en la medida en que se establecen conexiones permanentes con departamentos similares en diversas universidades de los países desarrollados, con las cuales se trabaja en proyectos conjuntos, y nuestros jóvenes 
profesores-investigadores pueden ir adquiriendo la competencia internacional que aún no tenemos, participar en publicaciones conjuntas, y en definitiva ir siendo parte de la ciencia mundial, pero en nuestro caso con fuertes repercusiones locales. En algunos de estos departamentos de universidades de Europa y Estados Unidos, con las que tenemos convenios, gran parte de nuestros profesores-investigadores han iniciado doctorados, o Ph.D., de tales universidades, en forma sándwich, con periodos en el exterior y trabajos de investigación en Loja, con profesores visitantes a veces y en otros casos usando las nuevas tecnologías (Internet, aulas virtuales, videoconferencia...). En varios años podremos contar con un cuerpo de doctores formados en el exterior y conectados internacionalmente con sus pares, pero sin que dejen por largos periodos sus respectivos grupos de trabajo en los CITTES, y por tanto la capacidad instalada va creciendo de forma ininterrumpida y fuertemente colaborativa. Todo ello repercutirá fuertemente en la calidad de la docencia, tanto presencial como a distancia.

La gestión específica del sistema de modalidad a distancia se realiza a través de las diferentes Áreas de trabajo de la Dirección General de Modalidad a Distancia, cuya acción se complementa con la curricular de las diferentes Escuelas:

- Coordinación Académica y Evaluación

- Material Didáctico

- Centros Universitarios

- Comunicación y Atención a Alumno

- Unidad de Virtualización

- Unidad de Procesos y Contabilidad

- Unidad de Videoconferencias

- Instituto de Pedagogía en Educación a Distancia

Algunos de los CITTES colaboran también directamente con el funcionamiento de la modalidad a distancia, como es el caso de los de informática, comunicación y producción audiovisual, diseño de Web y multimedia, sociedad electrónica, asesoría y desarrollo empresarial y social, etc.

\section{Los Centros Universitarios}

Son estructuras de apoyo para los alumnos de los diferentes lugares del país, con el fin de facilitar los procesos administrativos y académicos dirigidos desde la Sede Central. Estas estructuras de apoyo son imprescindibles por la característica de dispersión del alumnado, sirviendo de enlace entre éstos y la Sede Central. Se 
crearon inicialmente 34 Centros, y en la actualidad funcionan 93 en el territorio ecuatoriano y tres en el exterior: Roma, Madrid y New York, estos últimos surgen por la demanda social y el deseo de atender a la formación de nuestros emigrantes. Estos Centros Universitarios de apoyo tienen un tamaño muy variable, desde uno que atiende a más de 6000 alumnos, en Quito, con una infraestructura compleja, a centros en poblaciones pequeñas e infraestructura mínima que atiende a medio centenar de alumnos. En esta red de centros universitarios subyace también una visión país, y una forma de concebir el servicio educativo, dentro de un respeto a la igualdad de oportunidades. Es inviable que una pequeña ciudad tenga Universidad; la opción en casi todo Latinoamérica ha sido el hacer Extensiones Presenciales de las Universidades, con la carencia de profesores buenos y sólo centradas en dar clases. Por las diversas situaciones del entorno, estas extensiones suelen ser de mala calidad. La alternativa es no tener la posibilidad de estudios universitarios, y en ambas se favorece el éxodo de las generaciones jóvenes hacia las grandes ciudades; ésta es una de las razones más poderosas de la centralización de nuestros países, con su estela de problemas. Las condiciones para un desarrollo socioeconómico sustentable en las poblaciones del interior son de esta forma totalmente precarias, empezando por este aspecto relacionado con la formación superior de su propia gente; grandes sectores del interior de nuestros países vienen a ser entonces algo así como el sur del sur, cuya principal causa de exclusión es la educación superior de calidad. Con la Modalidad a Distancia (MaD), cuya calidad depende de la Sede Central, la situación puede ser totalmente diferente. Pero además los Centros Universitarios de la MaD pueden tener un gran impacto en la comunidad en la que se hace presencia de muy diversas maneras, no sólo con los grupos de estudiantes que como universitarios dan otro aire al lugar, sino también porque son entes de promoción cultural de la zona y favorecen su conectividad y apertura al mundo, y se constituyen en interesantes focos de desarrollo local. Además, son punto de conexión en todo el país de los diversos CITTES de la universidad, con lo que esto puede suponer para el desarrollo económico y social.

Desde el punto de vista académico los Centros Universitarios cumplen importantes funciones como promoción, información y prematrícula; entrega del material didáctico; recepción y devolución de evaluaciones a distancia; organizan la celebración de jornadas y evaluaciones presenciales, para las cuales viajan a todo el país los profesores de la Sede Central; son sede de tutorías y espacio motivacional de vínculo y comunicación para los estudiantes; etc.

Las posibilidades que las TICs nos brindan en los últimos años, han permitido también que cualquier tramite realizado en los Centros Universitarios pueda ser 
conocido de forma inmediata en la Sede Central y a la inversa, al estar conectados con un mismo sistema académico - administrativo. Además proporcionan conectividad mínima a través de Internet a los que no poseen este servicio en sus hogares, que lamentablemente en nuestro país aún es la inmensa mayoría.

En los Centros más pequeños los alumnos colaboran a través de autogestión, basada en la corresponsabilidad participativa de todos los estudiantes del Centro. Los Centros más grandes cuentan con personal contratado, además de ofrecer otros servicios de ayuda y promoción estudiantil como biblioteca, sistema de videoconferencia multicast, aulas, etc. Estos Centros facilitan también sus servicios a los Centros más pequeños.

De los 93 Centros Universitarios, 2 (Quito y Guayaquil) tienen carácter regional, 20 son provinciales, situados en la cabecera provincial, 54 son Centros Asociados de pequeño tamaño, 5 son Institucionales, vinculados a instituciones civiles o del Estado y que están dirigidos al personal de las mismas y apoyados con infraestructura de estas instituciones y 12 son Experimentales, aun no consolidados y que tienen un carácter provisional según la evolución del número de alumnos. Los Centros Internacionales en Nueva York, Madrid y Roma se preocupan por atender a los emigrantes que han salido del país, y además de permitir la continuación o el inicio de sus estudios universitarios, cumplen con una importantísima función de vínculo con su país y espacio de convivencia creativa en medio de las dificultades que se presentan en la población emigrante, son centro de integración con el país receptor y favorece un retorno digno a unos y un crecimiento profesional a los que deciden quedarse. Estos Centros atienden a diversos grupos en otros lugares de Estados Unidos, España e Italia, y son a su vez agencias de vinculación entre la UTPL y las universidades y demás entidades de esos países. En total el número de alumnos que atienden es de casi un millar entre los tres.

\section{LA MODALIDAD ABIERTA $Y$ A DISTANCIA $Y$ SU MODELO EDUCATIVO}

La Modalidad Abierta y a Distancia de la UTPL, en la actualidad, hace presencia en todo el territorio nacional, con un modelo propio que sigue las líneas generales de los Sistemas de Educación a Distancia mundiales pero con sus claves específicas que le permiten responder a las necesidades del país y de su gente, contribuyendo al desarrollo sociocultural de la comunidad. Desde el primer momento, la Modalidad Abierta y a Distancia ha sido coesencial al desempeño de la misión de la Universidad, por la función social que tiene, posibilitando el acceso a la educación superior a 
quienes por diversos motivos no pueden hacerlo de otra forma. Su desarrollo, en consonancia con las tendencias de nuestro tiempo, es tarea esencial en la Universidad y se acomete a través de sus órganos respectivos, teniendo en cuenta los diversos rasgos que la definen: Separación física entre el profesor y los alumnos, la acción formativa basada en materiales impresos, audiovisuales, nuevas tecnologías y medios de comunicación, el aprendizaje flexible, independiente y autónomo, una comunicación bidireccional y multidireccional, la necesidad de apoyo tutorial y una red de Centros universitarios para atender a una población dispersa geográficamente (García Aretio, 2002, pp. 28-35).

De la misma forma consideramos básico tener en cuenta los principios propios del sistema a distancia, ya que siguen vigentes, tanto o más que cuando nació esta modalidad, a pesar de que en estos momentos se acerquen a ella otros actores que no fueron privados de la educación superior en la etapa propia de sus estudios. Hoy en día, la incorporación de las nuevas tecnologías hace que la educación a distancia, además de atender a la necesidad de formación permanente, democratización de la educación o igualdad de oportunidades, pueda ser un componente valioso, alternativa o complemento de la educación tradicional.

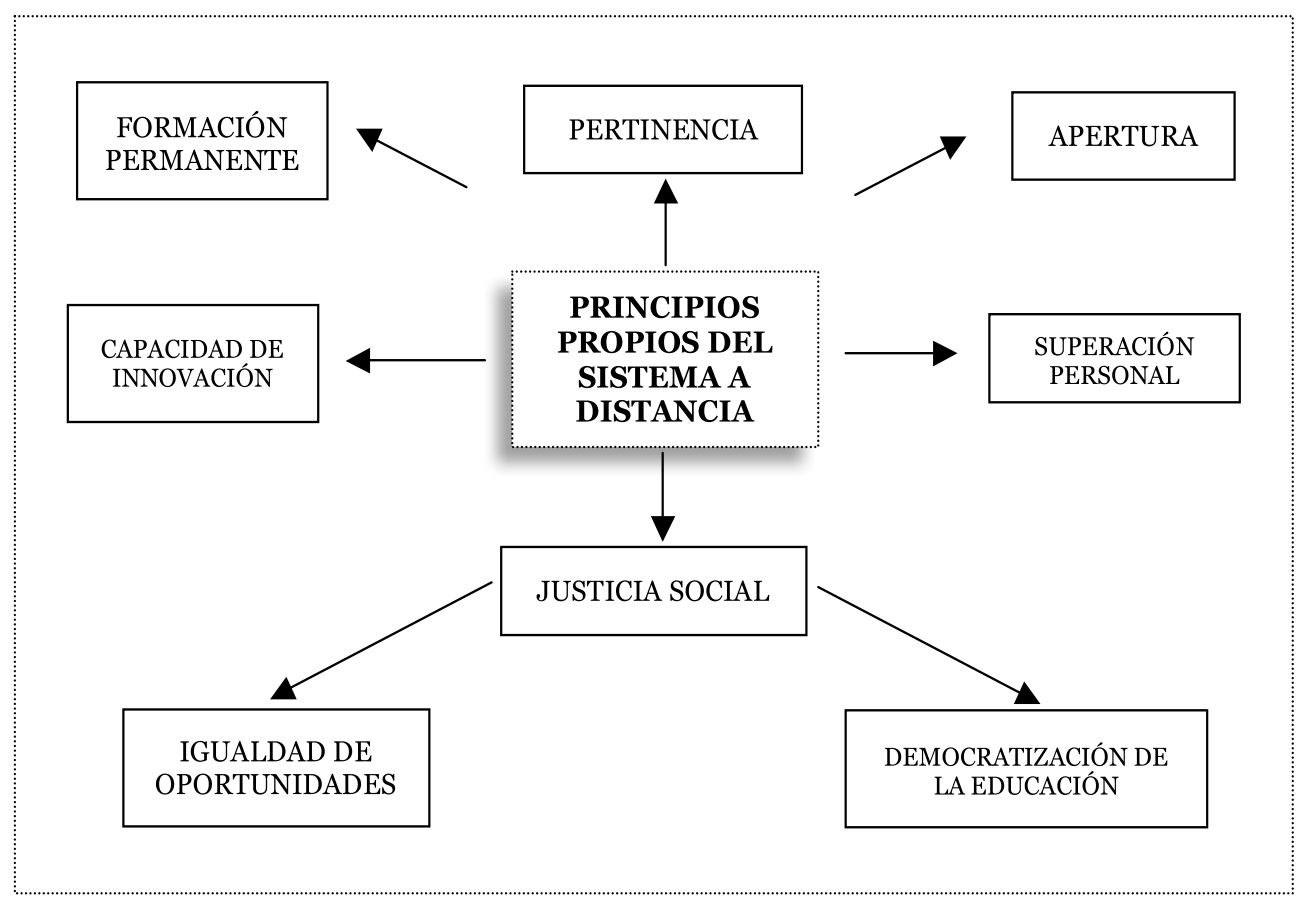


Así, no podemos olvidar las ventajas que significa estudiar a distancia, ya que permite al alumno compatibilizar responsabilidades laborales y familiares, estudiar la carrera que desee sin abandonar su lugar de origen y seguir formándose a lo largo de la vida, con un método idóneo que le permite adquirir conocimientos de forma creativa, despertar el gusto por la investigación y la actividad personal a través de trabajos sistemáticos y profundos, desarrollar el sentido de la responsabilidad, de la administración racional de su tiempo hasta encontrar el método personal de estudio, y la práctica de la autoevaluación como estrategia importante para el aprendizaje, sin olvidar la adquisición de hábitos de lectura de estudio y trabajo que le preparan para acometer funciones intelectuales superiores.

\section{Los objetivos de la Modalidad a Distancia en la UTPL}

\section{Generales}

- Ofrecer una igualdad de oportunidades o democratización de la educación posibilitando la profesionalización y formación universitaria a quien no puede, o no pudo obtenerla de otra forma, por razones de trabajo, de ubicación geográfica o por condicionamientos económicos, sociales o personales.

- Impulsar programas que den respuesta a las necesidades reales del país.

- Favorecer el entorno sociocultural de las comunidades donde hace presencia la modalidad de educación a distancia.

- Fomentar el uso educativo de las TICs.

\section{Específicos}

- Formar, capacitar, especializar y actualizar a estudiantes y profesionales universitarios en las distintas ramas del conocimiento humano, con elevado nivel científico, técnico y humanístico.

- Aplicar métodos y técnicas de aprendizajes idóneos, flexibles y eficientes, donde cada estudiante sea el artífice principal de su propia formación, mediante el autoaprendizaje.

- Fomentar la creatividad, el espíritu crítico, la libertad, la sociabilidad y los valores éticos, desde una pedagogía proyectivamente personalizada.

- Vincular la labor académica a la gestión, la investigación y la extensión universitaria a través de la responsabilidad y el esfuerzo personal, de tal 
forma que el estudiante sea capaz de aprender haciendo, hacer investigando e investigar creando con el fin de mejorar su entorno social.

\section{Desarrollo del modelo}

La Modalidad Abierta y a Distancia (MAaD) de la UTPL se concibe como una estructura compleja con diferentes planos interrelacionados. Este sistema educativo basa su accionar en una metodología flexible, en principios filosóficos, pedagógicos y de gestión universitaria, y en valores cristianos que le han conferido una identidad propia, no ajena, sin embargo, a la incorporación de elementos y logros diversos de la rica experiencia actual sobre educación a distancia.

El modelo educativo de la MAaD parte de la consideración del ser humano como hijo de Dios y por tanto susceptible de ir perfeccionando la dignidad que le corresponde, a través de un medio idóneo que es su formación humana y profesional desde los conocimientos universitarios. La MAaD tiene en cuenta las características y principios propios del sistema y se sitúa en el contexto socio-económico y laboral del hombre y la mujer ecuatorianos, de sus circunstancias y exigencias culturales y del entorno en el que se desenvuelve el estudiante, ya que todo ello puede facilitar o limitar la acción educativa, pero abiertos a la universalidad del conocimiento, esencial en la vida universitaria. Esta modalidad apoya su gestión en componentes que se encuentran armónicamente imbricados en el modelo y que son: el diseño curricular, el personal docente y de tutoría, los materiales educativos, la infraestructura física en la Sede y en los Centros Universitarios; así como en las nuevas tecnologías de la información y la comunicación (TICs), que facilitan los procesos y la interacción con los alumnos. Todo este conjunto está permanentemente retroalimentado por la evaluación-investigación, proporcionando información, que permite un mejoramiento continuo de los procesos y de la calidad del servicio educativo que se ofrece. 


\section{MODELO EDUCATIVO DE LA MODALIDAD ABIERTA Y A DISTANCIA DE LA UTPL}

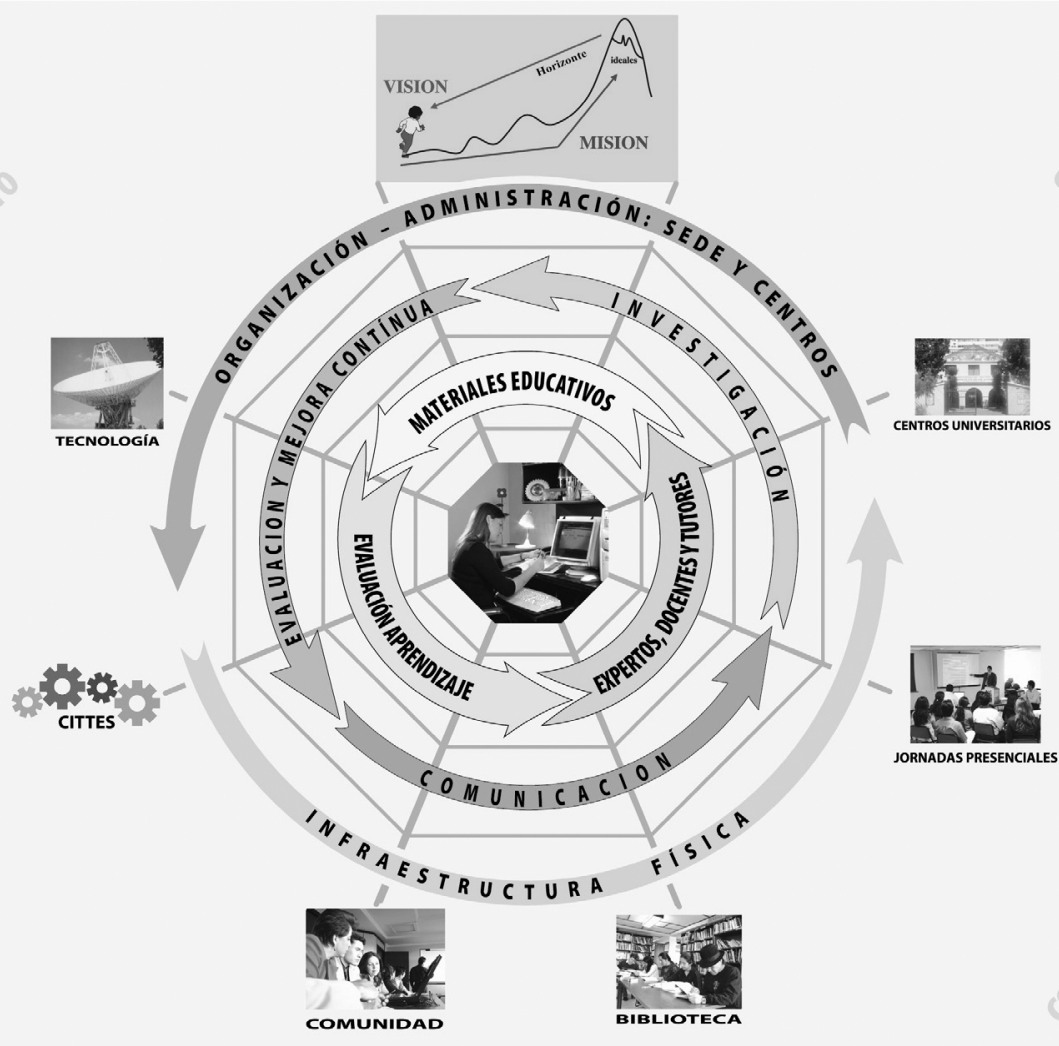

Los pilares que sostienen el sistema son: los expertos y docentes-tutores, los materiales educativos, la comunicación, la investigación y la evaluación, teniendo en cuenta en todo el proceso, al estudiante como actor principal. Asimismo estos componentes, se soportan en dos bases fuertes y sólidas que son la organizaciónadministración y la infraestructura física y tecnológica, tanto en la Sede como en los Centros Universitarios.

La gestión empieza por tener un horizonte claro (visión) hacia dónde caminar y saber como hacerlo (misión). Las claves están en un "liderazgo colegiado", en el "trabajo en equipo" y un compromiso firme con la institución y con la sociedad. Otros componentes que no podemos perder de vista son: el diseño curricular, los métodos, técnicas y estrategias pedagógicas, tutorías, etc. a las que se recurre para 
compensar la separación física y desarrollar la capacidad de aprendizaje autónomo en el estudiante a distancia. Elementos propios de nuestro modelo, que conviene destacar, son las Jornadas Pedagógicas de Formación Humana, el Seminario de Fin de Carrera y la Defensa de Tesis que constituyen instancias presenciales, que les permiten a los alumnos investigar, profundizar, y reflexionar en temáticas de importancia, actualidad e interés.

\section{Sistema centrado en el alumno}

Nuestro sistema educativo tiene como actor y protagonista al estudiante, en función de quien y para quién se planifica todo el proceso de enseñanza-aprendizaje. Concebimos al estudiante como crítico, espontáneo y colaborativo, emprendedor y con espíritu creativo.

Valores que la Modalidad a Distancia cultiva en los alumnos

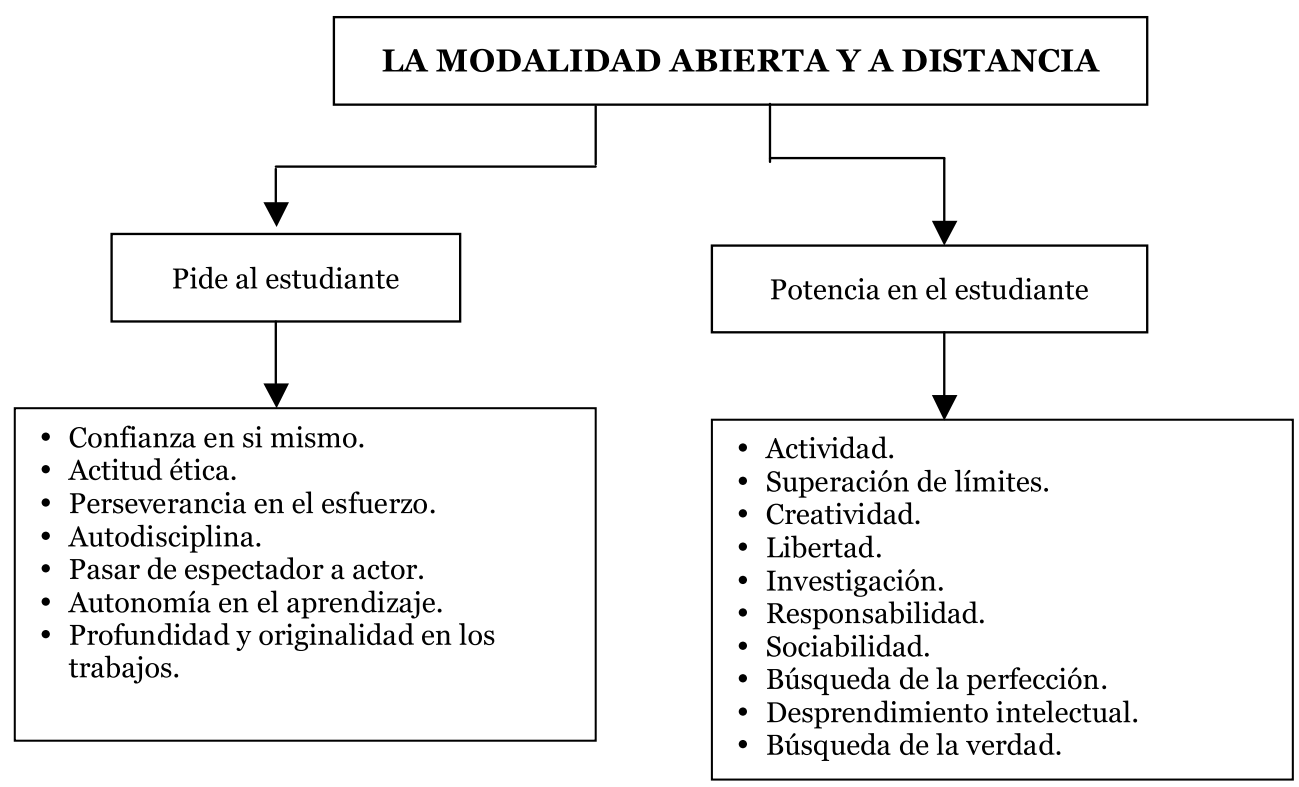




\section{Los Materiales Didácticos}

Una de las claves de nuestro modelo son los materiales: Libro de mercado, Guía Didáctica y Biblioteca Virtual en Internet. No estamos de acuerdo en lo que ha sido típico en la mayoría de las modalidades a distancia, es decir, el diseño específico de materiales; sobre todo, con base a los modelos instruccionales. Esto detuvo la educación una década en Latinoamérica, entre otras cosas porque eran simplistas y la amplitud del conocimiento no quedaba recogida en los mismos. En segundo lugar porque hay libros muy buenos en las diversas editoriales y disciplinas que no es necesario repetirlos y además se actualizan de forma permanente. A partir de estos libros de excelente calidad y actualizados se elabora y actualiza la Guía Didáctica que viene a ser en la Modalidad a Distancia, lo que la clase presencial en el sistema tradicional, suponiendo que en ésta se utilicen libros de texto, y no se tenga al profesor como fuente primaria de información, como en la Edad Media. Es decir que la Guía Didáctica se centra en elementos superiores de la función docente, más allá de los contenidos informativos: introduce, contextualiza, plantea objetivos, relaciona, señala los aspectos importantes, sintetiza, resuelve problemas, pone ejemplos... con la diferencia de que en vez de ser en directo y en presencia, se hace con la metodología a distancia, se prepara con mucha antelación y pensando en todos los posibles alumnos en las más diversas situaciones sociales y personales.

Otro de los aspectos claves para asegurar la calidad y estar seguros de que los estudiantes tienen acceso, al menos, a la bibliografía básica, es entregarles el material cuando realizan su matrícula y no esperar a que lo compren, sino incluirlo en el costo de la misma. Este material, compuesto por Texto Básico y Guía Didáctica, más materiales complementarios si los hubiere, por asignatura, se entrega en el momento de la pre-matrícula en cada uno de los Centros Universitarios del país o del exterior. La formalización definitiva de la matrícula depende de los procesos administrativos de la Sede Central. Por otra parte, para asegurar la posibilidad de ampliación en las consultas bibliográficas en los destinatarios geográficamente dispersos, nuestra universidad se ha preocupado mucho de ofrecer una amplia biblioteca virtual que está al servicio de todos los alumnos y profesores con más de 32 bases de datos de texto completo.

Los profesores principales de cada materia seleccionan del mercado los textos básicos convencionales en función de criterios de actualidad, rigor científico, didáctico-metodológico y congruencia con la asignatura; en base a ellos elabora la Guía Didáctica, que motiva, orienta, promueve la interacción y conduce al estudiante en el proceso de aprendizaje a través de diversos recursos pedagógicos. Algunas asignaturas incluyen CD Multimedia, videos y audio. La Guía Didáctica incluye 
Evaluaciones a Distancia (trabajos), concebidas como estrategia de aprendizaje que posibilitan en los alumnos el desarrollo de diversas competencias, mediante tareas y ejercicios de análisis, reflexión, aplicación de conocimientos, síntesis, evaluación, planteamiento de propuestas, etc. Otros recursos fundamentales son las herramientas pedagógicas de virtualización que le han posibilitado interacción, flexibilidad e inmediatez al sistema educativo de la Modalidad Abierta y a Distancia: La red de videoconferencias y el entorno virtual de aprendizaje, a los que nos referiremos más adelante.

\section{Expertos, profesores y tutores}

La vinculación de profesores a tiempo completo, junto con su formación de postgrado, aspectos tan poco frecuentes en las universidades de Latinoamérica, es otra de las claves de nuestro modelo. Los docentes están vinculados a unidades de investigación, son a su vez investigadores, aunque sea aún en una fase inicial; ya no les es ajena la investigación, tal y como sucede en las universidades desarrolladas. Estos profesores-investigadores, además de dar clase en la Modalidad Presencial, desarrollan su cátedra también en la Modalidad a Distancia llevando a la docencia el contexto de su experiencia de contacto con la ciencia real y su aplicación a través de su trabajo en los CITTES. La bimodalidad es una tendencia universal en estos momentos, ya que salvando las grandes universidades unimodales que nacieron como tales, hoy en día se da la tendencia a ofertar los programas en ambas modalidades.

El rol del profesor puede ser diverso:

Expertos: Profesionales que dominan una disciplina científica o área del conocimiento. Aparte de los autores de los libros de mercado, que podemos considerarlos como tales, son autores de alguno de los libros que no estén disponibles, o expositores principales en eventos específicos.

Profesores: Son docentes-investigadores, autores de la Guías Didácticas, tutores, evaluadores, expertos en las materias que imparten y que han sido formados en la metodología a distancia. Cumplen entre otras funciones: Diseñar el programa de estudio y planificar la asignatura; seleccionar el texto básico; elaborar la Guía Didáctica y otros recursos educativos; proponer actividades de aprendizaje, seguimiento y retroalimentación; dar tutoría presencial, telefónica, virtual en el EVA o en el sistema de videoconferencia satelital; coordinarse con la Unidad Académica; motivar y dinamizar el proceso de enseñanza aprendizaje; diseñar, receptar y calificar las evaluaciones a distancia y en presencia; y dirigir tesis y participar en proyectos de investigación y extensión en el CITTES correspondiente. 
Tutores: La función tutorial principal la realizan los profesores desde la Sede Central en horarios preestablecidos de cuatro horas semanales, a través de las diversas modalidades, ya que de acuerdo a la realidad ecuatoriana, no es posible mantener tutores permanentes en todas las asignaturas en los Centros Universitarios. En los Centros Universitarios se ofrecen tutorías específicas obligatorias para inglés y computación. En otras asignaturas en las que los alumnos encuentran dificultades, se ofrecen tutorías voluntarias. Se contempla diversos tipos de tutorías: presenciales, sean individuales o grupales; y a distancia: A través del teléfono, el EVA, la videoconferencia, el e-mail, e incluso el correo postal o el fax en algunos casos.

\section{El Entorno Virtual de Aprendizaje (EVA)}

Especial mención nos merece el proceso de virtualización que experimentó nuestra universidad. El comienzo fue un extraordinario desarrollo del CITTES correspondiente a computación, que fue el primero de los CITTES por ser área de desarrollo estratégico de la universidad. Hace unos ocho años, la conectividad de la universidad prácticamente se reducía a una computadora conectada a Internet con línea dedicada, y en muy poco tiempo contaba con salto satelital propio y todo el campus conectado, servicio de Internet a la ciudadanía y un cierto desarrollo en los grupos de redes, desarrollo de software y Web y multimedia. Se inició entonces el proceso de implementación de la modalidad online, con la asesoría de la Universidad Oberta de Catalunya, que fue muy exitoso desde el punto de vista técnico y de adquisición de know-how por parte de la universidad. Al principio fue una modalidad separada de nuestro sistema de educación a distancia y con algunas carreras experimentales, siguiendo la tendencia de carreras totalmente virtuales, pero la demanda en la ciudadanía fue muy escasa, particularmente por las condiciones de un país que en aquellos momentos tenía una penetración de Internet de no más del $3 \%$. Poco a poco fuimos reparando en el error estratégico y se pasó a una virtualización total de la Modalidad a Distancia como elemento complementario y opcional a la Modalidad Tradicional, más parecido a lo que sucedía en la UNED de España. Se formó, entonces la Unidad de Virtualización, cuyo objetivo era la investigación técnica y pedagógica de las herramientas online, y la implementación de la misma en todas las asignaturas de la Modalidad a Distancia. En poco tiempo, se disponía de campus online disponible para todo el alumnado en prácticamente todas las materias, que eran en total más de 500. De esta forma el estudiante podía hacer uso de las herramientas virtuales si contaba con los medios, pero de no ser así podía seguir sus estudios de la forma tradicional. Era una forma de adecuarnos a un país que no estaba preparado para el uso masivo de Internet, aunque nuestra universidad sí lo estaba. Actualmente, nuestro EVA es usado sistemáticamente por más de la 
tercera parte de los más de 20.000 alumnos a distancia, y empieza a ser herramienta de apoyo en numerosas materias de la Modalidad Presencial.

Desde el punto de vista técnico, pasamos del uso de plataformas comerciales a las de open source, investigando simultáneamente en varias de ellas, también en cuanto al tipo de herramientas disponible y su utilidad. Curiosamente fuimos optando por configuraciones cada vez más simples, en las que los aspectos relacionados con el aprendizaje fueran los centrales, especialmente los de comunicación profesoralumno y multidireccionales asincrónicas, así como los de secretaría virtual; la Guía Didáctica y materiales complementarios que pueden ser colgados por el profesor.

Otra herramienta fundamental relacionada con el EVA es la disponibilidad de una densa biblioteca virtual con numerosas bases de datos de texto completo y repositorio de Links a libros y materiales disponibles en Internet. De hecho, creemos que una de las mayores posibilidades para el desarrollo de la Modalidad a Distancia en las próximas décadas está en las bibliotecas virtuales, particularmente cuando las editoriales comiencen a bajar costos en los libros accesibles online. Actualmente estamos iniciando también nuestro repositorio de objetos de aprendizaje y video sobre demanda, para lo cual el único limitante es el ancho de banda disponible.

Mientras se iban desarrollando el EVA y la biblioteca virtual, la Universidad se dedicó a sustituir la página Web institucional por un concepto más relacionado con el de "portal". Actualmente se puede acceder fácilmente a toda la oferta académica, y demás informaciones de la universidad, matricularse en línea, consultar notas y saldos pendientes, calendario, horario de exámenes, etc. Todo esto fue posible gracias al desarrollo del sistema informático académico y financiero, en su mayor parte desarrollado por la Universidad, que permite, gracias a potentes bases de datos, el fácil procesamiento y acceso de la información académica y contable. Los que no tienen acceso personal a Internet, pueden acudir para ello a nuestros Centros Universitarios, y por supuesto todos nuestros profesores, administrativos y alumnos tienen cuenta de e-mail en nuestro dominio institucional: www.utpl.edu.ec, www. utplonline.edu.ec

\section{La red de videoconferencias}

El sistema de videoconferencia satelital, o aulas virtuales sincrónicas, cuenta con un centro de emisión de señal en Loja, desde donde el profesor puede desarrollar el tema o tutoría y ser difundida, en tiempo real, a 22 aulas distribuidas en el país, con tendencia en el futuro a tener en más centros, ya que el sistema satelital no tiene 
límites en la señal, como sí los tiene aún la videoconferencia dedicada o de video de doble vía. A través del satélite, tal y como si estuviéramos en presencia, se puede dar una clase magistral o servirse de presentaciones de power point, escribir en el pizarrón, enviar y contestar e-mail, conectarse a una página Web, poner un video y dialogar con los alumnos y estos entre sí, pero siempre el profesor es el que da paso a estas interacciones que pueden ser múltiples, tantas como aulas conectadas. Se utilizan para tutorías y jornadas de formación en pre y postgrado, actividades académicas y eventos nacionales e internacionales con expertos invitados.

El uso de las nuevas tecnologías, haciendo cultura en el país, es uno de nuestros aspectos claves para llegar a todos los lugares con un mismo mensaje tanto para los que pueden disponer de ellas, como para los que no pueden, al incorporar no sólo el EVA, con la virtualización de todas las carreras y cursos; sino las videoconferencias satelitales en 22 puntos del país, lo cual nos permite llegar en tiempo real a más de 2.500 alumnos simultáneamente y con ello disponer de profesores y expertos de primer nivel en todos los lugares, asegurando así la tutoría y la docencia, impartidas donde no habría posibilidades de conseguir buenos profesionales. En los Centros grandes, en las cabeceras provinciales, se utilizan estas aulas virtuales sincrónicas y se reúne en torno a las mismas a los alumnos y otros agentes de la zona, cuando se considera necesario en la docencia o en los actos académicos que tienen gran repercusión en el entorno, al igual que las participaciones de especialistas mundiales que oportunamente se contactan para su disertación en temas de interés. Así podríamos mencionar algunas de las intervenciones de este último año como la de Howard Gardner y el premio Nobel de Economía 2001, Joseph E. Stiglitz. Sería impensable que de otra forma pudieran tener acceso generalizado a estas personas sino fuera por estos medios.

Por otra parte, somos conscientes, que estos medios sincrónicos tienen una función didáctica más motivacional que cognoscitiva, pero aquella es muy importante en nuestro contexto, y su contribución al aprendizaje es esencial. El crecimiento en la utilización de horas del sistema en los últimos años responde al apoyo dado en tutorías y eventos para facilitar el conocimiento a los alumnos. También contamos con un sistema de Videoconferencia dedicada que se utiliza con frecuencia en los Centros Regionales de Quito, Cuenca y Guayaquil para diversos motivos: postgrados, reuniones, conferencias hacia la Sede Central en Loja, etc. 


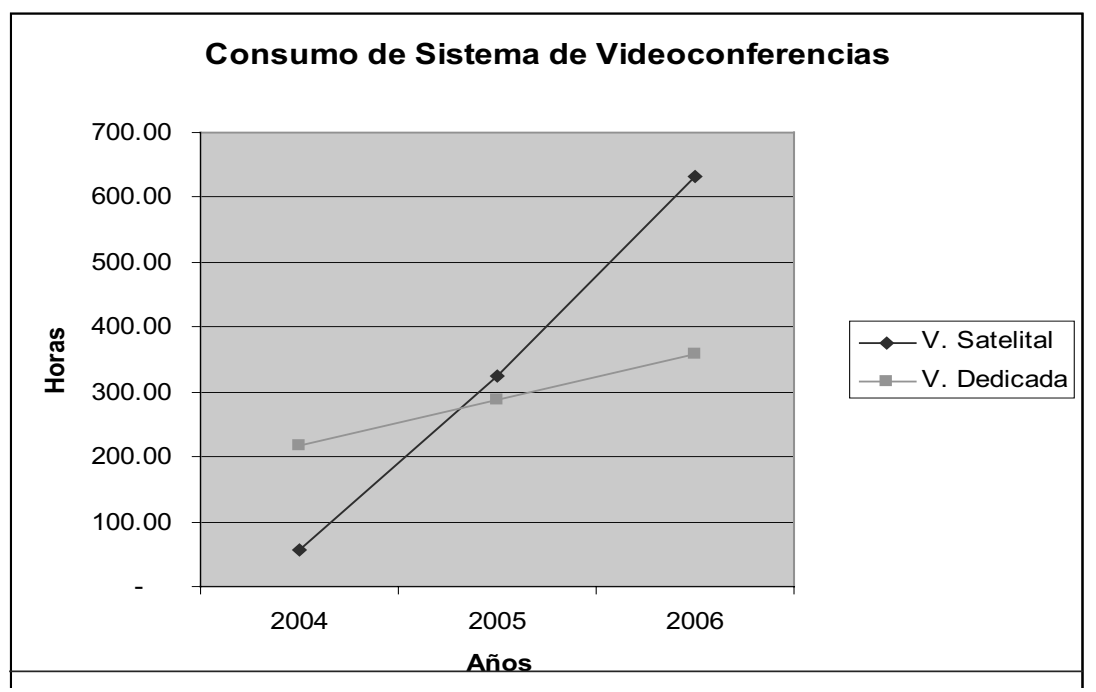

\section{Uso pedagógico del Call-Center}

Como innovación tecnológica, hemos desarrollado también los servicios pedagógicos del concepto de Call Center, o sistema de información telefónica, viene a ser una herramienta muy útil en nuestro sistema, a través del cual los alumnos a distancia pueden consultar sus inquietudes sirviéndose de diferentes líneas: una de consulta automática, fundamentalmente utilizada para conocer las notas cuyo servicio se ofrece las 24 horas al día, otra para la atención personalizada por operadora para consultas administrativas y docentes en general, a través del PBX, es decir, un número asociado a varias líneas lo cual permite que diferentes personas puedan contestar a través de un mismo número. La línea de llamadas gratuitas del 1-80o, facilita la información más general de la Universidad. El Call Center nos permite el control de las respuestas de llamadas y seguimiento de las mismas, así como prever la devolución de las no atendidas, con el fin de satisfacer a la persona que al llamar no logró su objetivo de comunicación. Esta moderna tecnología nos posibilita dar una atención al estudiante con el fin de satisfacer sus inquietudes y necesidades, y a la vez nos ayuda en la difusión o notificación específica de acontecimientos o eventos puntuales.

\section{Evaluación del aprendizaje}

La evaluación comprende todo el proceso educativo y se operativiza a través de autoevaluaciones, evaluaciones a distancia y evaluaciones presenciales. Las 
autoevaluaciones son cuestionarios de carácter formativo con preguntas objetivas y actividades sugeridas, para el autocontrol y la retroalimentación en el proceso del aprendizaje. Se incluyen en las Guías Didácticas. Las evaluaciones a distancia constituyen una estrategia de aprendizaje y comprende dos partes: objetiva y de ensayo. Tiene un valor equivalente al 30\% de la calificación total, son dos en el semestre, su presentación, por parte del alumno es obligatoria. Las evaluaciones presenciales constituyen en estos momentos un elemento que da fiabilidad al sistema. Son realizadas por los profesores de la Sede Central que se desplazan a los diferentes Centros Universitarios, y existe todo un departamento encargado de la fiabilidad extrema del proceso, para evitar fraudes. Se realizan tres evaluaciones presenciales, dos al finalizar cada bimestre, que abarcan la totalidad de los contenidos programados, y uno supletorio. Tienen un valor equivalente al 70\% de la nota global, pero el estudiante sólo aprueba con el 70\% de la nota global (evaluación a distancia, sobre el 30\% y evaluación presencial sobre el 70\%)

\section{Jornadas, Seminarios y Pasantías}

Otros elementos propios de nuestro modelo, que conviene destacar, son las Jornadas Pedagógicas, las Pasantías Profesionales, el Seminario de Fin de Carrera y la Defensa de Tesis. Constituyen importantes espacios presenciales para complementar la formación del estudiante y propiciar el encuentro, la investigación y la reflexión.

Las Jornadas Pedagógicas son de tres clases: Jornada de Asesoría de Sistema, destinada a todos los alumnos que se matriculan por primera vez. Con el fin de que se familiaricen con la institución y adquieran confianza y seguridad a través de la orientación en la metodología propia del sistema y su reglamentación. Jornada Temática o de Formación Humana, dirigida a los alumnos de segundo a séptimo ciclos. Versan sobre temas de interés y actualidad en la formación pedagógica o humano-cristiana, y contribuyen a cimentar los valores y consolidar la formación integral de los estudiantes. Y Jornada Técnico Profesional, dedicada a los alumnos de octavo o décimo ciclo. Tiene como objetivo asesorar en la Práctica Profesional, el Proyecto de Investigación y Seminario de Fin de Carrera. Estas jornadas pueden complementarse con pasantías profesionales diversas.

El Seminario de Fin de Carrera constituye una exigencia académica para egresar. Comprende actividades grupales, conferencias, debates, mesas redondas, sesiones plenarias, etc. Incluye, a su vez, un trabajo previo de investigación. Se desarrolla en la Sede Central en Loja con una duración de tres o cuatro días. 
Finalmente, la tesis es una exigencia académica para optar por la licenciatura y una vez desarrollada debe ser defendida ante un tribunal en la Sede Central. En los Centros del exterior puede ser expuesta por videoconferencia.

\section{La Investigación en Educación a Distancia}

Una de las cuestiones clave que suelen ser motivo de crítica hacia la Modalidad a Distancia es la dificultad para hacer investigación, que es una de las dimensiones de la Universidad, para que podamos entenderla como tal. Diremos, al respecto que la crítica es cierta en alguna manera, sobre todo por la tendencia en muchos contextos a confundir la educación a distancia con la capacitación, centrada en la entrega de contenidos. De hecho, la mayor parte de lo que en Latinoamérica se consideran programas de educación a distancia suelen ser más bien capacitación, que tiene también una función importante para el desarrollo cultural y económico, pero es diferente de la educación a distancia en cuanto administración de un currículum universitario, de pregrado o postgrado, que incluya dimensiones profesionales y otras más integrales de formación humana e intelectual. Pero también, en la forma en que se lleve a cabo la educación a distancia, en sus enfoques didácticos puede ponerse más o menos énfasis en la investigación; sucede igual en la modalidad presencial. Nosotros hemos tratado de cuidar este aspecto de diversas maneras, como exponíamos anteriormente. Pero esto no es propiamente investigación en sentido estricto, sino una parte de la formación referida a que el alumno desarrolle determinadas competencias.

La investigación científica, el contacto directo con la realidad actual de la ciencia en un área concreta, es asunto de los profesores, que si son verdaderos profesores universitarios serán de una u otra forma profesores-investigadores. Como apuntábamos al principio, éste es uno de los problemas fundamentales de la universidad latinoamericana y sus estructuras organizativas. Si consideramos a las universidades de Latinoamérica como un todo, menos del 10\% de sus profesores hacen auténtica investigación, contrastada internacionalmente y validada por sus pares; y las estructuras universitarias tampoco favorecen que esto cambie. En nuestro caso, como ya hemos comentado, los profesores-investigadores, a pesar de ser noveles muchos de ellos, trabajan a tiempo completo la gran mayoría, dedicando dos tercios de su tiempo a investigar y realizar proyectos en la sociedad en esas incubadoras de investigación socialmente relevante que son los CITTES. Una tercera parte de su tiempo lo dedican a dar clases de forma presencial y/o a distancia, según la organización de la Escuela, por tanto en su docencia hablan con el referente de lo que han vivido en su contacto con la ciencia real. 
Hay otra dimensión de investigación específica de la Modalidad a Distancia y es la que tiene por objeto de investigación la Modalidad a Distancia, que por innovación, características, etc., forma parte central de la ciencia de nuestro tiempo. En este sentido tenemos un Instituto de Pedagogía en Educación a Distancia, que es el CITTES dedicado a investigar sobre el tema. Vinculados a su entorno, también colaboran en sus diferentes investigaciones profesores de otras áreas: educación, informática, comunicación, etc.

Pero hay aún una dimensión peculiar de la investigación en educación a distancia que hemos venido trabajando en la Universidad con resultados prometedores y de fuerte repercusión nacional. Hemos de comenzar resaltando el giro, desde 1999, que dimos en nuestra Modalidad a Distancia al enfoque de las tesis de grado (tesina) con el desarrollo de programas corporativos dirigidos a todos o muchos de los alumnos egresados de una determinada Escuela. Un equipo de profesores investigadores de alguno de los CITTES prepara una investigación país o regional, que se ejecuta en cascada a través de los tesistas, que están dispersos geográficamente, usando una Guía Didáctica que conduce el trabajo de los alumnos, así como de una orientación adecuada y el estudio de la bibliografía correspondiente, en forma de gran equipo de trabajo. Con esto se ha conseguido que las tesis sirvan para algo y no sean simples documentos archivados en una biblioteca que nadie consulta y que sirven para muy poco, pues en la mayoría de las ocasiones en las tesis individuales se investigan aspectos intrascendentes y muy poco aplicables en una sociedad donde deberían aprovecharse las investigaciones para su desarrollo. Se ha logrado también que los egresados terminen las tesis en tiempos cortos y no sean los eternos tesistas típicos de nuestro medio, debido en gran parte a la carencia de orientación y el ambiente adecuados para la realización de las mismas. Pero sobre todo se ha podido investigar aspectos que tienen una repercusión en el país por el interés de los temas y la amplitud de la muestra, y la forma en que está dirigido el estudio por equipos de profesoresinvestigadores, que son los responsables últimos del trabajo.

Recogemos, a modo de ejemplo, algunos programas de la Escuela de Educación, que es las más antigua, y fue con la que se inicio la experiencia. Ya hay más de una veintena de programas también en Contabilidad, Inglés, Ciencias Jurídicas, Gestión Ambiental, etc.

- Diagnóstico de la capacidad intelectual con el test de RAVEN a los alumnos de Educación Básica de los establecimientos educativos del Ecuador (1.107 titulados). 
- Diagnóstico y prospectiva de la interculturalidad como realidad nacional y como eje transversal del currículo de la educación básica ecuatoriana (672 titulados).

- La educación en valores como eje transversal de la reforma curricular y su prospectiva en la educación básica del Ecuador (731 titulados).

- Autoevaluación del Sistema de Estudios a Distancia de la Escuela de Ciencias Contables y Auditoría de la UTPL, desde el criterio de los estudiantes (545 titulados).

- El Hecho Migratorio y su Impacto Socioeducativo (560 titulados).

\section{Evaluación y mejora continua}

La pertinencia y la calidad de la Educación Superior, conceptos clave tal como fuera enfatizado por la Asamblea General de la UNESCO sobre Educación Superior en 1998 en París, no son ajenos a la Modalidad a Distancia en nuestro contexto latinoamericano. El rigor académico, la innovación y la pertinencia de la institución en general y de los programas en particular están siendo el núcleo de reflexión mundial, y todo intento de educación a distancia serio, debería incorporar estas dimensiones en el núcleo de su actuación. Como hemos visto, la intención de pertinencia social se refleja en muchas de las dimensiones de la Modalidad a Distancia de la UTPL; también la calidad como evaluación institucional con el objetivo de la mejora continua y la incorporación de innovaciones que puedan conducir al desarrollo académico y a la pertinencia social, aunque inicialmente este esfuerzo, que creemos natural de toda universidad que desee ser tal, no fuera nada formalizado.

En el 2002 la universidad se vio involucrada, como agentes ejecutores, en el proyecto del Banco Interamericano de Desarrollo Centro Virtual para el Desarrollo de Estándares de Calidad para la Educación Superior a Distancia en Latinoamérica y el Caribe, auspiciado por el Consorcio-Red de Educación a Distancia (CREAD) y la Asociación Iberoamericana de Educación Superior a Distancia (AIESAD). www. utpl.edu.ec/centrovirtual/ A partir de ese momento hemos seguido investigando también técnicamente en el tema de la calidad en la Educación a Distancia, y como resultado del Congreso Calidad y Acreditación Internacional en Educación Superior a Distancia, celebrado en la Universidad Técnica Particular de Loja, se creó el Instituto Latinoamericano de Calidad en Educación Superior a Distancia (CALED), cuya secretaría ejecutiva está a nuestro cargo. www.utpl.edu.ec/caled/

El CAL-ED se propone unir esfuerzos institucionales con el objetivo de promover y fortalecer la capacidad de las Universidades Latinoamericanas y del Caribe en la 
consecución de una oferta de Educación a Distancia de Calidad ya que tiene presente el papel que la misma desempeña en el desarrollo de nuestros países. Su misión, por tanto, es contribuir al mejoramiento de la calidad en la educación superior a distancia en todas las instituciones de América Latina y el Caribe que ofrezcan este tipo de estudios. Para ello brinda asesorías en Educación a Distancia y en el proceso de autoevaluación de los Programas que lo requieran. Promueve la cultura de la evaluación de la calidad y contribuye a la elaboración de directrices e instrumentos para la evaluación, acreditación y certificación de Titulaciones, Programas y Servicios de Educación Superior a Distancia y genera mecanismos de reconocimiento de la calidad basados en criterios, indicadores y estándares comunes para la Educación Superior a Distancia, coordinando esfuerzos y colaborando con las Agencias nacionales de acreditación en estos sistemas. La Junta Directiva del CAL-ED, está conformada por las entidades promotoras de la iniciativa: CREAD, AIESAD, Virtual Educa y la UTPL, y posee un Consejo Asesor formado por importantes instituciones como la OEA, OUI, OEI, etc., y dos Consejos Académicos, compuestos por las instituciones latinoamericanas y del contexto europeo y norteamericano.

\section{Oferta Académica y Alumnado}

En Latinoamérica la oferta educativa a distancia no es tan grande como parece, suelen ser muy escasos los programas a distancia de larga duración. Se ofrecen pocas licenciaturas, a pesar de que son necesarias. Son mucho más frecuentes los programas de postgrado de corta duración, es decir, los diplomados. Las maestrías totalmente a distancia, también son muy escasas, estas se ofrecen, fundamentalmente, en programas semipresenciales. En la UTPL se ofrece una amplia oferta educativa. Creemos que los grandes números de algunas carreras nos ayuda a poder mantener otras de interés social, aunque por si solas no fueran autosustentables. En la actualidad se ofrecen 22 Licenciaturas o carreras de pregrado cuya duración es de 8 o 10 semestres más el tiempo de duración de la tesis y, en postgrados se ofrecen: 5 Diplomados de un semestre de duración, 3 Especialidades de dos semestres de duración y 5 Maestrías de cuatro semestres de duración.

\section{Pregrado (licenciaturas)}

Como hemos señalado nuestra universidad oferta 22 carreras universitarias en todo el país y en los Centros del exterior, pudiendo llegar con el mismo tipo de educación tanto a personas ya formadas que acceden a una segunda carrera, 
como a otras personas que son simplemente bachilleres y por primera vez tienen la oportunidad de entrar en la universidad. El acceso es prácticamente igual para personas que viven en una gran ciudad como para personas que viven en pequeños poblados de la selva, costa o sierra o incluso de las Islas Galápagos; tenemos matriculados tanto empresarios y profesionales muy formados, como indígenas, campesinos o profesionales no cualificados, a personas adultas lo mismo que a jóvenes; todos con el mismo programa y la misma exigencia, y en general las mismas posibilidades. Es decir, la educación a distancia no discrimina a nadie, democratiza y universaliza la educación y siempre que se tenga una oferta amplia, se dará oportunidad para elegir aquella profesión que se desee o la capacitación que se necesite. Obviamente las posibilidades de acceso dependen del costo, nos hemos esforzado en que sea lo más bajo posible. Una media de 450 US\$ por semestre, incluyendo libros de mercado y guías.

El diseño curricular corresponde a las diferentes Escuelas, la mayoría bimodales, que son las que tienen la visión conceptual de las mismas, coordinadas por área (Socio-humanística, Administrativa, Técnica y Biomédica) y bajo la tutela de la Dirección General Académica. Sin embargo existe una Coordinación Académica en la Modalidad a Distancia y el Instituto de Pedagogía en Educación a Distancia que ayudan a la administración del curriculum en aquellos aspectos que tiene que ver con la metodología a distancia, la formación de los profesores en estos aspectos metodológicos, el seguimiento, control y evaluación de sus procesos específicos, etc.

Tenemos 13 carreras en el Área Socio-humanística: Educación (8 especialidades), Educación Infantil, Psicología, Comunicación Social, Derecho, y Ciencias Humanas y Religiosas; 7 carreras en el Área Administrativa: Contabilidad y Auditoria, Economía, Administración de Empresas, Banca y Finanzas, Gestión Pública, Turismo y Secretariado Ejecutivo Bilingüe; 1 carrera en el Área Técnica: Informática; y 1 Carrera en el Área Biomédica: Gestión Ambiental.

\section{Postgrados}

En Postgrados se ofertan 5 Diplomados: Editor de Medios Impresos, Desarrollo Local y Salud, Pedagogías Innovadoras, Gerencia del Desempeño Empresarial, Dirección y Administración de Empresas; 3 Especialidades: Diagnóstico Intelectual, Gestión y Liderazgo Educativo, y Gerencia y Planificación Estratégica, y 5 Maestrías: Desarrollo de la Inteligencia, Psicopedagogía, Talentos y Creatividad, Gerencia y Liderazgo Educacional, Gerencia en Salud para el Desarrollo Local, y Educación a Distancia. Todos los postgrados son a distancia, con algún componente presencial. 


\section{Capacitación Continua}

En capacitación continua se ofertan cursos diversos a las empresas y entidades del sector público o de diferentes sectores sociales, además de los cursos abiertos que se ofrecen al público en general a través del EVA o del sistema tradicional de educación a distancia y programas especiales.

\section{Crecimiento permanente de alumnos}

Como ya hemos comentado, la UTPL es esencialmente bimodal, esto significa también que nuestra modalidad presencial tiene prácticamente la exigencia de dedicación exclusiva y numerus clausus definido por las posibilidades de aplicación de un currículum verdaderamente presencial. El número de alumnos presenciales es del orden de los 3.00o, en cambio a distancia el volumen es parte de su estrategia. Número total de alumnos Modalidad a Distancia Abril/Agosto 2006:

- Pregrado

- Postgrado

- Programas especiales

- Formación continua TOTAL
18.650

2.890

.870

1.353

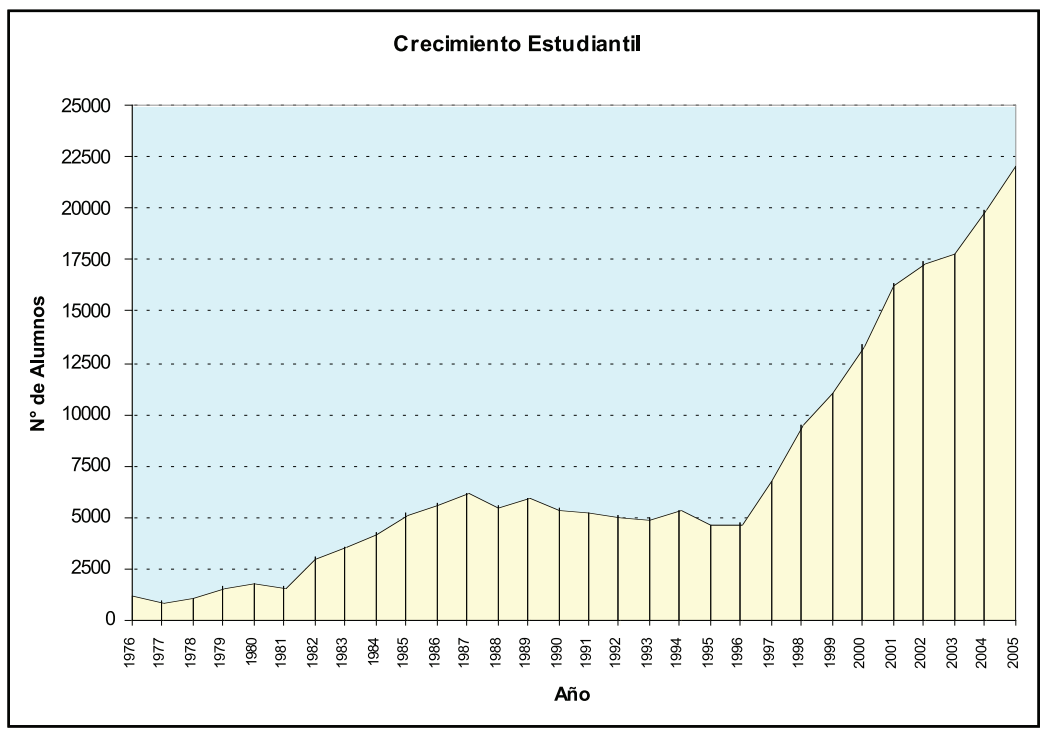




\section{PROYECCIÓN INTERNACIONAL DE LA UTPL}

La internacionalización de la Universidad es una de las dimensiones clave de la realidad universitaria actual, esto por muchas razones, desde la globalización del conocimiento y las comunicaciones, y los referentes de calidad, a las propias exigencias de universalidad del conocimiento. La apertura internacional de nuestra Universidad ha sido una de nuestras dimensiones fundamentales, que tiene especial impacto en la Modalidad a Distancia. Recogemos, seguidamente, algunos aspectos destacables respecto a la misma, además de nuestros Centros en el exterior, que ya hemos comentado

\section{Principales proyectos Internacionales en los que la UTPL ha participado en los últimos años}

- Proyecto Rueda: Evaluación de los programas de educación a distancia. Programa ALFA II de la Comunidad Europea.

- Centro Virtual para el Desarrollo de Estándares de Calidad para la Educación Superior a Distancia en América Latina y el Caribe. (BID)

- Postgrados y Doctorados en Educación a Distancia. Programa ALFA II de la Comunidad Europea.

- Erasmus Mundus - Net - ACTIVE (AIESAD-EADTU Credit Transfer In Virtual and distance Education), de la Comunidad Europea.

- Concepción, situación y prospectiva de la Educación a Distancia en América Latina (COSYPEDAL), de la Cátedra UNESCO de Educación a Distancia (CUED) de la UNED de España.

- Red Eva - Espacios virtuales de aprendizaje. (AECI/España)

- Investigación y estudios sobre eficacia adecuación y calidad educativas: evaluación y control sistemático. AECI/ España - Universidad de Sevilla.

- Red de Formación de Formadores. RIF-FOMA, del COLAM/OUI.

- Fortalecimiento de las capacidades e-learning de América Latina. INWET, Alemania.

\section{Participación como invitados en Congresos Internacionales en el año 2006}

- Seminario Internacional de Evaluación y Acreditación de las Instituciones de Educación a Distancia. UAPA, Santiago-República Dominicana. 
- Taller Latinoamericano de Reflexión sobre Aseguramiento de la Calidad en e-learning y Educación a Distancia. UCLA, Barquisimeto-Venezuela.

- III Seminario Interamericano sobre calidad en Educación Superior a Distancia. Virtual Educa. Bilbao-España.

- Foro Estatal 2006 de E-Learning: Analizando las potencialidades de la educación virtual en la academia la industria y los servicios. QuerétaroMéxico.

- Congreso Mundial de Educación a Distancia. La Megauniversidad a Distancia del siglo XXI. UNAD, Bogotá-Colombia.

- II Congreso de Educación a Distancia de Panamá: La Educación Superior a Distancia y sus retos ante el mundo globalizado. UNADP, Panamá.

- X Congreso CREAD/MERCOSUR/sul 2006 Calidad, Aprendizaje y Tecnología: Desafío de la Educación a Distancia. U. Católica del Norte, Antofagasta-Chile.

- XIII Congreso Internacional de Tecnología y Educación a Distancia. UNED, San José-Costa Rica.

- IV Congreso Internacional sobre tecnologías de la información, comunicación y educación a distancia (CITIDED 2006) - IV CREAD del Caribe. Santo Domingo-República Dominicana.

- Fortalecimiento de capacidades e-learning de América Latina, Lima-Perú.

- Online Educa capitulo Berlín. Berlín.

- European Association for Distance Teaching Universities (EADTU) Conference, Tallin-Estonia.

- XV Encuentro Internacional de Educación a Distancia. UDG, GuadalajaraMéxico.

\section{Pertenencia a Redes Internacionales de Educación a Distancia y cargos ocupados en las mismas}

\begin{tabular}{|c|c|c|}
\hline Siglas & Institución & Participación UTPL \\
\hline AIESAD & $\begin{array}{c}\text { Asociación Iberoamericana de Educación } \\
\text { Superior a Distancia }\end{array}$ & $\begin{array}{c}\text { Vocal del Consejo } \\
\text { Directivo }\end{array}$ \\
\hline CREAD & Consorcio Red de Educación a Distancia & $\begin{array}{c}\text { Miembro Consejo } \\
\text { Ejecutivo }\end{array}$ \\
\hline GDLN & $\begin{array}{c}\text { Red Global de Aprendizaje para el Desarrollo } \\
\text { del Banco Mundial }\end{array}$ & $\begin{array}{c}\text { Representante en } \\
\text { Ecuador }\end{array}$ \\
\hline
\end{tabular}




\begin{tabular}{|c|c|c|}
\hline $\begin{array}{l}\text { VIRTUAL } \\
\text { EDUCA }\end{array}$ & Virtual Educa & $\begin{array}{l}\text { Representante en } \\
\text { Ecuador }\end{array}$ \\
\hline ATEI & $\begin{array}{c}\text { Asociación de Televisión Educativa } \\
\text { Iberoamericana }\end{array}$ & Asociado y colaborador \\
\hline ICDE & $\begin{array}{l}\text { Internacional Council for Open and Distance } \\
\text { Education }\end{array}$ & $\begin{array}{l}\text { Coordinación en } \\
\text { Ecuador }\end{array}$ \\
\hline ISTEC & $\begin{array}{l}\text { Ibero American Science \& Technology } \\
\text { Education Consortium }\end{array}$ & $\begin{array}{l}\text { Representante en } \\
\text { Ecuador }\end{array}$ \\
\hline CEDIA & $\begin{array}{l}\text { Consejo Ecuatoriano Desarrollo de Internet II } \\
\text { (Asociado a la red CLARA) }\end{array}$ & $\begin{array}{l}\text { Presidencia de la Red en } \\
\text { Ecuador }\end{array}$ \\
\hline CAL-ED & $\begin{array}{l}\text { Instituto Latinoamericano y del Caribe de } \\
\text { Calidad en Educación Superior a Distancia }\end{array}$ & Secretaría Ejecutiva \\
\hline
\end{tabular}

\section{Asesorías internacionales en los últimos años}

Hemos realizado asesorías diversas para la implementación de sistemas de educación a distancia a una veintena de universidades en América Latina: México (2), Honduras (1), República Dominicana (4), Venezuela (2), Perú (7), Bolivia (3), Paraguay (1); además de diversas asesorías a universidades y otras instituciones en el país.

\section{Colaboración con la cátedra UNESCO de la Universidad Nacional de Educación a Distancia (UNED-España)}

Somos los editores del formato impreso y electrónico de la Revista Iberoamericana de Educación a Distancia (RIED), que se configura como el instrumento de la Asociación Iberoamericana de Educación a Distancia (AIESAD) para la difusión de trabajos relevantes de carácter científico, experiencias e información bibliográfica, dentro del ámbito de la enseñanza/aprendizaje abierto y a distancia en sus diferentes formulaciones y presentaciones. Y colaboramos también con el Boletín Informativo BENED de la Cátedra UNESCO de la UNED en la recopilación de noticias sobre Educación a Distancia en Iberoamérica. 


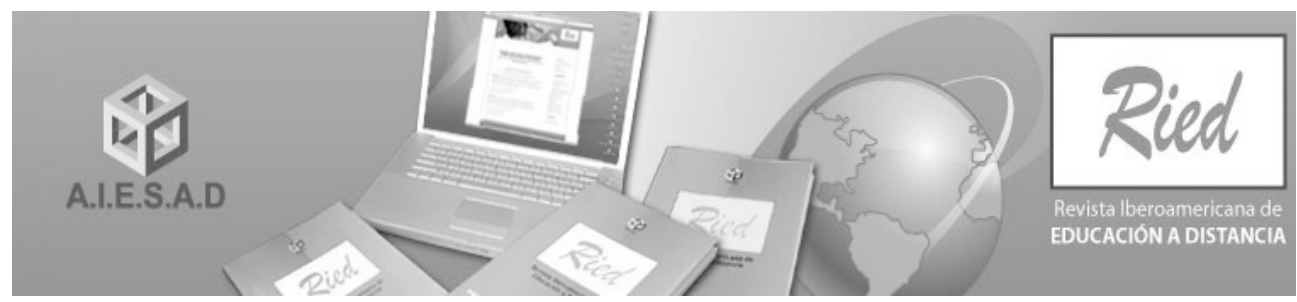

\section{Proyecto Chiquitos}

Una de las experiencias más originales y prometedoras que estamos llevando a cabo en el ámbito internacional es lo que denominamos Proyecto Chiquitos. La Chiquitania es una región del oriente boliviano en el Departamento de Santa Cruz, frontera con el Brasil, enormemente deprimida desde el punto de vista socioeconómico, pero que posee unas peculiares características culturales herederas de las misiones jesuíticas y una extraordinaria riqueza natural. Allí se encuentra una extensión de la Universidad Católica Boliviana a la que nuestra universidad está ayudando con la implementación de unidades de investigación apropiadas (similares a los CITTES, pero de menor dimensión), con profesores y tesistas de grado, con el desarrollo tecnológico y con la creación de la Modalidad de Educación a Distancia, vinculada académicamente con la UTPL mediante convenio con la Universidad Católica Boliviana. Se trata de un proyecto de colaboración Sur-Sur, mediado por tecnología y teniendo como elemento central la educación a distancia en zonas campesinas de fuerte componente indígena.

\section{PERSPECTIVA SISTÉMICA DE LA EDUCACIÓN A DISTANCIA}

Quisiéramos enfatizar, finalmente, que la educación a distancia es un sistema muy complejo, aunque no muy complicado, que se desarrolla de forma vital, como el embrión humano, subsistema a su vez del complejo sistema universitario en el que debe insertarse plenamente. Este sistema está integrado por muy diversos componentes, como los que hemos expuesto, de cuya interacción y regulación precisas, como en los sistemas biológicos, depende su supervivencia y evolución. Una idea muy lejana de los reduccionismos a que estamos acostumbrados en educación a distancia. Especialmente las TICs podrían jugar un papel muy destacable, pero sólo si se centran en el uso en lugar de mito que tanto las adorna, y se integran con los otros componentes del sistema. Hoy en día se tiende a considerar a la educación superior desde la perspectiva de una gestión del conocimiento (Silvio, 200o) podemos considerar diferentes funciones (generación, transferencia y conservación), 
procesos (docencia, investigación y extensión) y componentes (productos, recursos, estructuras, actores, tecnologías, normas y contenidos), y las relaciones entre todos ellos y con su ambiente socio-cultural, económico y político; pero enfatizando el porqué y el para qué del hecho educativo, es decir el contenido humano y axiológico de la institución universitaria. De hecho, uno de los elementos en los que más se insiste actualmente respecto a la educación a distancia es el rescate de lo humano sobre lo tecnológico o instrumental, la relación con un proyecto de vida personal y social, y el sueño en los más altos horizontes y valores que dan sentido a la vida. Efectivamente, los diversos componentes específicos de un sistema de educación a distancia, subsistema del sistema de gestión del conocimiento que es la educación superior: currícula, materiales, docentes, estudiantes, metodología, tecnología, gestión, evaluación, costos... deben estar íntimamente articulados por un "modelo educativo", y éste por la visión y misión integral de la universidad, y su apertura al contexto universal. Toda consideración a la calidad ha de hacerse, entonces, desde esta concepción integral, modulada por los valores humanísticos que expresan la visión y misión institucionales y su apertura.

\section{REFERENCIAS BIBLIOGRÁFICAS}

AA.VV. (2003). La Educación a Distancia y la Educación Virtual en Latinoamérica. Seminario Internacional sobre Universidades Virtuales en América Latina y el Caribe. Quito - Ecuador: IESALC-ORCILAC (UNESCO).

AA.VV. (2004). La educación superior virtual en América Latina y el Caribe. México: ANUIES - IESALC (UNESCO).

AA.VV. (2005). Hacia las Sociedades del Conocimiento. Paris: UNESCO

AA.VV. (2005). Calidad y acreditación internacional en educación superior a distancia (Memorias del I Congreso CREAD - Andes y Virtual Educa Ecuador). Loja, Ecuador: Universidad Técnica Particular de Loja.

Aguilar Feijó, R. M. (2004). La Guía Didáctica, un material educativo para promover el aprendizaje autónomo. Evaluación y mejoramiento de su calidad en la Modalidad Abierta y a Distancia de la UTPL. Revista Iberoamericana de
Educación a Distancia 7: 1/ 2, 179-192.

Bunge, M. (1988). Ciencia y desarrollo. Buenos Aires: Siglo Veinte.

De Ferranti, D., et al (2003). Closing the Gap in Education and Technology. Washington: World Bank.

García Aretio, L. (2002). La Educación a Distancia. De la Teoría a la Práctica. Barcelona: Ariel.

García Guadilla, C. (1996). Conocimiento, educación superior y sociedad en América Latina. Caracas: Nueva Sociedad.

Mena, M., comp. (2004). La educación a distancia en América Latina; Modelos, tecnologías, realidades. Buenos Aires: La Crujía - Stella - ICDE - UNESCO.

Romero Fernández, L. M., Rubio Gómez, M. J. (2002). Concepción sistémica de la educación superior a distancia $y$ universidad bimodal: Una vía hacia la calidad en Latinoamérica. Experiencia de la Universidad Técnica Particular de 
Loja. XI Congreso Internacional sobre Tecnología y Educación a Distancia. San José de Costa Rica.

Romero Fernández, L. M. (2004). Un enfoque realista de las políticas de investigación: Experiencia de la Universidad Técnica Particular de Loja.LaEduc@ción(OEA), $\mathrm{N}^{0} 139-140$, I-II.

Romero Fernández, L. M.; Rubio Gómez, M. J. (2005). Integrando la Educación a Distancia, la investigación y el servicio a la sociedad en el contexto latinoamericano. XI Encuentro Iberoamericano de Educación Superior a Distancia - VI Encuentro Virtual Educa. México D. F.

Romero Fernández, L. M.; Rubio Gómez, M. J. (2006). Creación y puesta en marcha del CAL-ED. Universidad Técnica Particular de Loja - Ecuador. [en línea] Disponible en : www.utpl.edu.ec/caled [consulta 2007, 10 de enero]

Romero Fernández, L. M. (2006). Quality and Social Pertinence in the Use of ICT from a Global Point of View: The Role of the Particular Technical University of Loja. Internacional Conference GUIDE-
2006. Rome

Rubio Gómez, M. J.; Romero Fernández, L. M. (2001). Aportes específicos de la educación a distancia a la investigación. IX Encuentro Iberoamericano de Educación Superior a Distancia. Cartagena de Indias - Colombia.

Rubio Gómez, M. J. (2002). Orientaciones y Metodología para la Educación a Distancia. Loja: Universidad Técnica Particular de Loja - Ecuador.

Rubio Gómez, M. J. (2003). Memoria del Centro Virtual para el Desarrollo de Estándares de Calidadparala Educación Superior a Distancia en América Latina y el Caribe. BID N. ATN/SF-7867-RG. Loja: Universidad Técnica Particular de Loja.

Silvio, J. (2000). La virtualización de la universidad. Caracas: IESALC/ UNESCO.

UNESCO (1988). Conferencia mundial sobre la educación superior. París: UNESCO.

UTPL(1971-2007). Documentos. Universidad Técnica Particular de Loja. Loja: Universidad Técnica Particular de Loja - Ecuador

\section{PERFIL ACADÉMICO Y PROFESIONAL DE LOS AUTORES}

María José Rubio Gómez, Dra. en Filosofía y Ciencias de la Educación, UNEDEspaña. Del 88/97 Directora Centro UNED-Baleares. Actualmente: Directora Modalidad Abierta y a Distancia, Universidad Técnica Particular de Loja; miembro Comisión especial de Educación a Distancia y Virtual, Consejo Nacional de Evaluación y Acreditación del Ecuador (CONEA-Ecuador). Coordinadora Proyecto Centro Virtual para el Desarrollo de Estándares de Calidad, auspiciado por el BID y otros en evaluación de la calidad de la educación a distancia.

E-mail: mjrubio@utpl.edu.ec 
Luis Miguel Romero Fernández, Licenciado en Biología y Filosofía, Doctor en Medicina por la Universidad de Zaragoza, España. Rector-Canciller de la Universidad Técnica Particular de Loja (Ecuador). Miembro de los consejos directivos de AIESAD, CREAD, y OUI. Director del Instituto Latinoamericano de Calidad en Educación Superior a Distancia (CALED).

E-mail: lmromero@utpl.edu.ec

DIRECCIÓN DE LOS AUTORES

Universidad Técnica Particular de Loja.

Ap. 11-01-608.

Loja-Ecuador

Fecha de recepción del artículo: 17/01/07

Fecha de aceptación del artículo: 05/03/07 